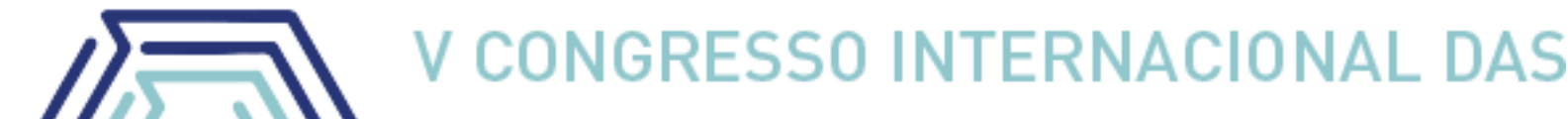 LICENCIATURAS COINTER - PDVL 2018
}

\section{A UTILIZAÇÃO DE UM EXPERIMENTO INVESTIGATIVO NO ENSINO DE ÁCIDOS E BASES}

\section{THE USE OF AN INVESTIGATIVE EXPERIMENT IN THE EDUCATION OF ACIDS AND BASES}

Apresentação: Pôster

\begin{abstract}
Yuri Miguel da Silva ${ }^{1}$; Renata Joaquina de Oliveira Barboza ${ }^{2}$; Leandro Soares da Silva $^{3}$; Sebastião Lucas de Farias ${ }^{4}$; Magadã Lira ${ }^{5}$
\end{abstract}

\section{DOI: https://doi.org/10.31692/2358-9728.VCOINTERPDVL.2018.00179}

\section{Introdução}

O ensino de química nas escolas é muitas vezes abordado de forma tradicional fazendo com que os alunos memorizem várias fórmulas, reações e propriedades, sem relacionar a teoria com a parte prática da disciplina. Esse tipo de metodologia é um dos principais fatores de desinteresse dos alunos em relação à disciplina de química.

A experimentação no Ensino de Química, no processo de ensino-aprendizagem tem sua importância justificada quando se considera sua função pedagógica de auxiliar o aluno na compreensão de fenômenos e conceitos químicos. A necessidade dos alunos de se relacionarem com os fenômenos sobre os quais se referem os conceitos justifica a experimentação como parte do contexto escolar, sem que represente uma ruptura entre a teoria e a prática (PLICAS; PASTRE; TIERA, 2010). Por isso, a grande importância da utilização da experimentação nas aulas de química.

Desse modo, as aulas experimentais, além de permitirem que os alunos conciliem a teoria com a prática é uma forma de que os alunos possam trocar ideias com o professor e com os demais alunos, e também de relacionar a química com o cotidiano dos próprios.

\footnotetext{
${ }^{1}$ Licenciatura em Química, IFPE- Instituto Federal de Pernambuco, yuridasilvamiguel13@hotmail.com

2 Mestranda em Educação em Ciências e Matemática, Universidade Federal de Pernambuco-CAA, renata_joaquina@hotmail.com

3 Mestrando Profissional em Química, Universidade Federal Rural de Pernambuco, Leandro.ifpe.química@gmail.com

${ }^{4}$ Licenciatura em Química, IFPE- Instituto Federal de Pernambuco, s.lucas100alvirubro@hotmail.com

${ }^{5}$ Professora Doutora, IFPE- Instituto Federal de Pernambuco, magada.lira@vitoria.ifpe.edu.br
} 
Com isto, este trabalho tem por objetivo apontar o uso dos experimentos investigativos nas aulas de química no processo de aprendizagem dos estudantes referente ao conteúdo de "Ácidos e Bases”.

\section{Fundamentação Teórica}

A disciplina de química é vista atualmente pelos estudantes como uma das mais difícéis do Ensino Médio, devido ao ensino marcado pela descontextualização e sem o uso de atividades que de fato estimulem a participação ativa dos mesmos. O conteúdo de Ácidos e Bases por exemplo, é composto por diversos conceitos que podem ser abordados dentro de um contexto que envolvam a participação dos estudantes, com conexões cotidianas simples e eficazes, contudo na maioria das vezes é tratado de maneira que não desperta a atenção dos estudantes por promover a reprodução de conteúdo e memorização de conceitos.

Como a química é uma ciência que possui um viés experimental, é importante que os professores façam uso dos experimentos químicos em sala de aula de forma a potencializar o processo de ensino e aprendizagem e instigar a curiosidade dos estudantes. Todavia, muitos professores apontam que a falta de laboratórios e/ou a falta de materiais e reagentes na escola dificultam a realização de experimentos no ambiente escolar. Nesta perspectiva, evidenciamos o uso de materiais de baixo custo e do cotidiano dos estudantes, assim como a utilização da sala de aula para realização das práticas experimentais, quando no caso exista a inviabilidade do laboratório e a presença desses problemas apontados anteriormente.

Desta forma, salientamos as contribuições das práticas experimentais na escola, que segundo Francisco Jr., Ferreira e Hartwig (2008), viabilizam um maior envolvimento dos alunos que os conduzem à reflexão racional dos fenômenos e ao desenvolvimento cognitivo de conceitos, articulando teoria e prática, a fim de não tornarem a execução dos experimentos um recurso apenas mecânico e repetitivo de ensino, mostrando dessa forma que o papel do professor é relevante, uma vez que é ele quem direcionará os caminhos da experimentação, seja ilustrativa ou investigativa - maneira está mais difícil de ser conduzida.

No sentido de maior significação dos experimentos no processo de ensino e aprendizagem, salientamos a utilização da experimentação investigativa, pois permite aos estudantes a utilização dos conhecimentos prévios por meio de suas hipóteses para solução do problema levantado pelo professor no início da aula, assim como possibilita situações que viabilizam a alfabetização científica a partir do uso do aspecto investigador dos estudantes. 
Segundo Guedes (2010), o ensino por investigação, leva os alunos a pensar, debater, justificar as ideias e também, aplicar seus conhecimentos em diversas situações. Partindo desses objetivos, os alunos precisam ter: curiosidades, iniciativa, criatividade, raciocínio e argumentação, para que a atividade seja considerada como investigativa. Para isso, o professor deve planejar com cuidado sua prática, de forma a proporcionar momentos que favoreçam a metodologia de ensino investigativo, sempre buscando as ideias dos estudantes e realizando reflexões acerca do conteúdo, mediando o conhecimento e direcionando-o para o viés científico.

O papel do professor no ensino investigativo não se restringe apenas a escolha $\mathrm{e}$ elaboração da situação problema a ser estudada, inclui-se também o de incentivar a participação dos estudantes, de modo ao professor intervir para relembrar instruções e apontar desvios do grupo, como de mesma forma seu trabalho de intervenção deve estar na medida certa, nem demasiadamente para não bloquear o raciocínio dos alunos, nem intervir pouco para não haver morosidade no trabalho e desvios na discussão (GUEDES, 2010).

\section{Metodologia}

O trabalho se configura como um estudo interventivo, realizado em uma Escola de Referência em Ensino Médio, localizada na cidade de Salgadinho-PE e teve como participante 22 (vinte e dois) alunos da $1^{\mathrm{a}}$ série do Ensino Médio, de (1) uma turma e todas atividades foram realizadas por Licenciandos e Licenciados em Química - IFPE-CVSA.

Antes da intervenção o professor apresentou aos alunos o assunto que seria abordado, cujo tema era "Ácidos e Bases". Depois disso, a intervenção foi realizada em dois momentos o primeiro da realização do experimento investigativo "Preparando um indicador ácido-base natural de açaí (Euterpe oleracea)", neste experimento os alunos investigavam qual eram as substancias que poderiam ser ácidas ou básicas no seu cotidiano e o segundo da avaliação da atividade.

Antes da realização do experimento foi perguntado aos alunos alguns conceitos básicos sobre o tema, como: O que são ácidos? O que são base? E quais são os ácidos e bases que eles conhecem no cotidiano deles? Depois disso começamos à desenvolver o experimento, primeiro fazendo o preparo do extrato do açaí. E depois utilizando alguns materiais do cotidiano deles (suco de laranja, água sanitária, solução de $\mathrm{HCl}$, solução de $\mathrm{NaOH}$, vinagre), para eles descobrirem se são ácidos ou bases. 
As análises foram realizadas a partir dos dados recolhidos dos questionários respondidos pelos alunos, que tinha as seguintes questões:

1. A utilização do experimento no Ensino de Química proporciona um melhor aprendizado?

2. Os experimentos investigativos ajuda no entendimento dos conteúdos?

3. Quando associamos os assuntos dado em sala de aula com experimentos investigativos você consegue ter um melhor aprendizado?

4. O experimento realizado ajudou a entender o assunto melhor?

5. O que são ácidos?

6. O que são bases?

7. Depois de realizado o experimento, quais reagentes você identificou como ácidos e como bases?

\section{Resultados e Discussões}

A utilização do experimento "Preparando um indicador ácido-base natural de açaí (Euterpe oleracea)" ajudou a ilustrar o conhecimento dos alunos no assunto que já tinha sido apresentado a eles de forma teórica pelo professor em sala de aula, objetivando aumentar a aprendizagem do aluno no conteúdo em questão que é os Ácidos e as Bases.

Depois do experimento ser realizado pelos alunos, foi aplicado um questionário que foi respondido pelos alunos de forma individual. Este questionário aponta que $95 \%$ dos alunos relataram que a utilização do experimento no ensino de Química proporciona um melhor aprendizado, porque a forma experimental ajuda os alunos a ilustrar um princípio teórico e demonstrar um fenômeno que pode ser abstrato, ou seja, muito difícil de entender só na forma teórica (Figura 1).

Figura 1: A utilização do experimento nas aulas de Química na visão dos alunos. Fonte: Própria

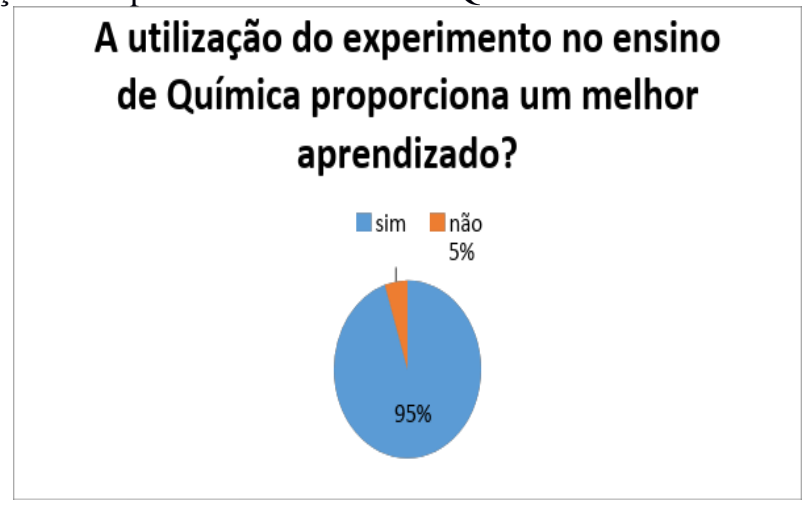

Ao perguntar aos alunos se é importante utilizar os experimentos investigativos nas aulas de Química, 90\% responderam que sim e 10\% responderam que não. Isso pode ser 
percebido no gráfico abaixo que aborda a socialização dos conteúdos que são dados em sala de aula com experimentos investigativos em relação à aprendizagem dos alunos, pois, além de ilustrar ou construir um determinado tópico de aula, podem ainda ser aliados a materiais ou fenômenos observados no cotidiano servindo de ponte entre um conceito que pode inicialmente parecer abstrato e coisas que vivemos no dia-a-dia que por muitas vezes nos passam despercebidos (Figura 2).

Figura 2: Os experimentos investigativos quando associados com os conteúdos na visão dos alunos. Fonte: Própria

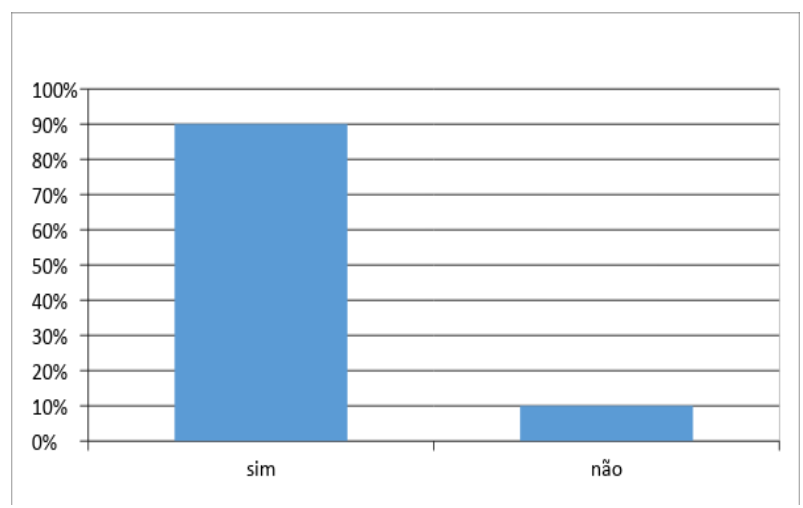

Ao perguntar aos alunos "O que são ácidos?" $80 \%$ dos alunos afirmaram que ácidos são substâncias que em meio aquoso liberam $\mathrm{H}^{+}$. Essa resposta pode ser observada quando o Estudante A respondeu: "Os ácidos são todas as substâncias que em água liberam o cátion $H^{+}$”. Com isto, verifica-se que a resposta que os alunos utilizam está de acordo com o livro que eles utilizam em sala de aula.

Depois foi perguntado aos alunos "O que são bases?" $85 \%$ dos alunos afirmam que bases são substâncias que em meio aquoso liberam $\mathrm{OH}^{-}$. Essa resposta pode-se observar quando o Estudante B respondeu: "As bases são todas as substâncias que em água liberam o ânion $\mathrm{OH}^{-}$. . Desta forma, podemos concluir que novamente os alunos utilizam respostas que eles aprenderam através dos livros didáticos.

Ao questionar os estudantes se os reagentes que foram utilizados na intervenção (suco de laranja, água sanitária, solução de $\mathrm{HCl}$, solução de $\mathrm{NaOH}$, vinagre) eram ácidos ou bases, eles responderam o seguinte: Suco de Laranja- Ácido- coloração rosa; Água Sanitária- Base coloração verde clara; Solução de HCl- Ácido- coloração vermelha; Solução de NaOH- BaseRoxo clara; Vinagre- Ácido- vermelha (Figura 3). Estas respostas estão de acordo, pois, quando mergulhamos estes reagentes são adicionados ao extrato de açaí, irão apresentar coloração que caracterizam se eles são ácidos ou bases. Para serem ácidas as soluções mostrariam uma coloração rosa a vermelha e para serem bases precisaria mostrar uma 
coloração roxa clara a verde.

Figura 3: Resultado da coloração que os reagentes apresentaram depois da intervenção. Fonte: Própria

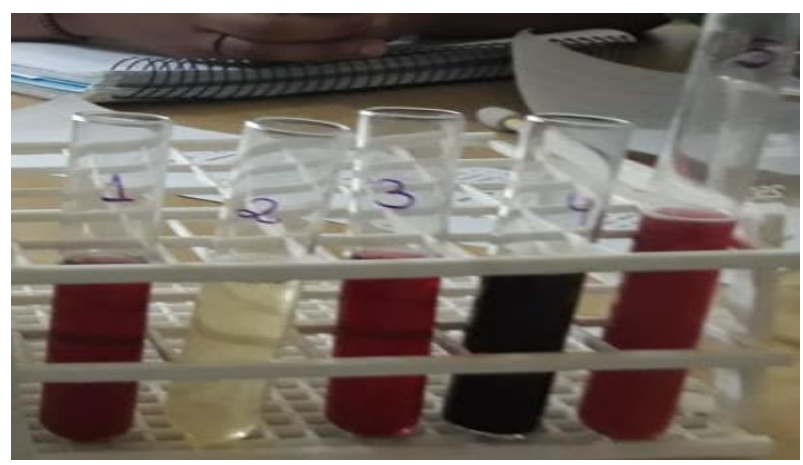

\section{Conclusões}

Através dos resultados e discussões pode-se concluir que é muito importante a utilização dos experimentos nas aulas de química, pois, além dos professores utilizarem atividades diferenciadas em sala de aula, os experimentos investigativos quando bem executados permitem o melhor aprendizado e retenção de conteúdos por parte dos alunos e é inegável a sua contribuição para estimular e despertar o interesse dos mesmos na aprendizagem e prática de ciências.

Com isso, pode-se concluir que quando é utilizado à prática experimental de cunho investigativo associado à contextualização, os estudantes têm um êxito maior, confirmando assim, a prática de utilizar os experimentos investigativos para justificar a teoria apresentada nas aulas. Desse modo, a Química torna-se uma ciência bem explorada, por fazer parte do nosso dia a dia e por fazer parte na evolução tecnológica, é de suma importância da ênfase na forma como o professor aborda em sala de aula os assuntos relacionados ao ensino de Química.

\section{Referências}

FRANCISCO JUNIOR, W. E.; FERREIRA, L. H.; HARTWIG, R. Experimentação Problematizadora: Fundamentos Teóricos e Práticos para a aplicação em salas de aula de ciências. Revista Química Nova na Escola, nº 30, novembro, 2008.

GUEDES, S. S. Experimentação no ensino de ciências: atividades problematizadas e interações dialógicas. Dissertação (Mestrado Profissional) - Universidade de Brasília, Brasília, 2010.

PLICAS, L. M. A; PASTRE, I. A; TIERA, V. A. O. O uso de práticas experimentais em Química como contribuição na formação continuada de professores de Química. In: Encontro Nacional de Ensino de Química, 15, 2010, Brasília. Anais... Brasília, 2010. 